\title{
EL REDUCTO INGLÉS DE SANCTI PETRI O DE LACY: UNA FORTIFICACIÓN COSTERA \\ DE LA GUERRA DE LA INDEPENDENCIA DE ESPAÑA EN LA PLAYA DE CAMPOSOTO (SAN FERNANDO, CÁDIZ)
}

\section{THE ENGLISH REDOUBT OF SANCTI PETRI OR DE LACY: A COASTAL FORTIFICATION FROM THE SPANISH WAR OF INDEPENDENCE ON CAMPOSOTO BEACH (SAN FERNANDO, CÁDIZ)}

\section{Josefa MARTÍ SOLANO ${ }^{1 *}$ y Lourdes MÁRQUEZ CARMONA ${ }^{1 * *}$}

\author{
${ }^{1}$ Centro de Arqueología Subacuática del Instituto Andaluz del Patrimonio Histórico, Avda. Duque de \\ Nájera 3, 11002, Cádiz \\ * Correo electrónico: josefa.marti@juntadeandalucia.es \\ ** Correo electrónico: lourdes.marquez.carmona@juntadeandalucia.es
}

\begin{abstract}
Resumen: Durante el período invernal del año 2010 quedaron al descubierto con el descenso de la marea y como consecuencia de un fuerte temporal, las improntas de unas estructuras excavadas en los niveles de marismas en la playa de Camposoto (San Fernando, Cádiz). Fue el arqueólogo Antonio Sáez Espligares, subdirector del Museo de Municipal de San Fernando (Cádiz), mientras paseaba por la playa, quien se percató de este hallazgo, poniéndolo en relación con el Reducto inglés de Sancti-Petri o de Lacy. Esta fortificación aparecía referenciada en las fuentes textuales y cartográficas, pero se carecía de evidencias arqueológicas y se desconocía, por tanto, su ubicación exacta. El presente artículo relata y describe este hallazgo, relacionando los escasos restos materiales que han perdurado hasta nuestros días con la información histórica disponible. Esta documentación identifica este enclave como parte del sistema de defensa costera de la Bahía de Cádiz en el marco de la Guerra de la Independencia de España. Su uso pervivió hasta los hechos históricos protagonizados por los “Cien mil hijos de San Luis" en 1823, durante la Guerra Realista y el Trienio Liberal.
\end{abstract}

Palabras Clave: fortificaciones, Guerra de Independencia (1808-1814), San Fernando (Cádiz), Sancti Petri, geomorfología, paleopaisaje, Fougueux (navío de línea), naufragio, pecios, Centro de Arqueología Subacuática del Instituto Andaluz del Patrimonio Histórico.

\begin{abstract}
During the winter period of 2010, traces of structures excavated in the level grounds of mud flats on Camposoto beach (San Fernando, Cádiz) were exposed with the ebb tide and as a result of a heavy storm. It was the archaeologist Antonio Sáez Espligares, deputy director of the Municipal Museum of San Fernando (Cádiz), while walking along the beach, who noticed these traces and connected them with the English redoubt of Sancti-Petri or de Lacy. This fortification had been referenced in textual and cartographic sources, but there was no archaeological evidence of its exact location. This paper relates and describes this finding and establishes a link between the few physical remains that have been preserved to this day and the historical information available. This documentation places this outpost as part of the coastal defence system of the Bay of Cádiz in the context of the Spanish War of Independence which lived through the historical events starring the "One Hundred Thousand Sons of St. Louis" in 1823, during the Royalist War and the Liberal Triennium.
\end{abstract}

Keywords: fortifications, War of Independence (1808-1814), San Fernando (Cádiz), Sancti Petri, geomorphology, paleolandscape, Fougueux (ship of the line), shipwrecks, wrecks, Centre for Underwater Archaeology of the Andalusian Institute of Historical Heritage.

Sumario: 1. Introducción. 2. Descripción del hallazgo. 3. Su representación en la cartografía histórica. 4. Contextualización histórica. 5. Plan de defensa de la Isla de León. 6. El Reducto inglés del campo de Sancti Petri o de Lacy. 7. Conclusiones. 8. Agradecimientos. 9. Fuentes de Información. 


\section{Introducción}

En enero de 2010, la entonces Delegación Provincial de Cultura de la Junta de Andalucía en Cádiz se puso en contacto con el Centro de Arqueología Subacuática, dependiente del Instituto Andaluz del Patrimonio Histórico, para solicitar una visita de su personal técnico a fin de valorar la aparición de unos restos localizados en la zona intermareal de la Playa de Camposoto (San Fernando, Cádiz). Estos habían quedado al descubierto tras los recientes temporales sufridos en este litoral, que habían provocado en algunos lugares la pérdida de gran cantidad de arena.

El hallazgo fue comunicado por D. Antonio Sáez Espligares, subdirector del Museo Histórico Municipal de San Fernando (Cádiz) quien, paseando por la playa en horas de bajamar, pudo fotografiar un conjunto de improntas de unas posibles estructuras. El técnico las puso en relación con una pequeña fortificación de la Guerra de la Independencia de España, construida en esa zona durante el asedio del ejército napoleónico. Podía identificarse así con uno de los reductos levantados para la defensa de la costa sur del istmo de Cádiz, concretamente con el Reducto inglés de Sancti Petri, construido en 1811 y posteriormente reutilizado en 1823 y rebautizado como Reducto de Lacy.

Esta fortificación formaba parte de la 1a línea de defensa de San Fernando y Cádiz durante el asedio por los franceses a la bahía gaditana de 1810 a 1812, en el marco histórico de la Guerra de la Independencia de España. Se desconocía la ubicación de este reducto pero sí existía documentación gráfica que mostraba en cartografía de la época su emplazamiento.

Se debió esperar a un nuevo descenso de la marea para poder visualizar las improntas, ya que con la pleamar la zona quedaba completamente cubierta por el agua. Durante esta segunda visita la impresión del técnico arqueólogo fue que el nivel de arena había aumentado considerablemente durante los cinco días transcurridos desde el hallazgo. La consecuencia fue que los restos que estaban visibles en esta ocasión resultaban ahora mucho más difíciles de interpretar, al hallarse en ciertas zonas la silueta de la estructura enterrada bajo la nueva capa de sedimento de arena, provocada por la acción de la marea y el viento.

Es necesario remarcar que una de las particularidades que presentan los hallazgos arqueológicos en zona intermareal es una efímera visualización.
Han de confluir una serie de circunstancias climatológicas muy adversas de regímenes de viento, durante fuertes temporales, que provoquen además intensos movimientos mareales, para conseguir la pérdida suficiente de sedimento que permita que el objeto o el yacimiento vuelva a ser visible. Esta combinación de factores aleatorios no es fácil, pero cuando sucede, la misma naturaleza se encarga, en un tiempo mínimo, de volver ese espacio a su estado original. Esto significa que la posibilidad de acceder y documentar este tipo de hallazgos suele ser mínima, y cuando se da esta circunstancia, el plazo del que se dispone para efectuar un análisis, también es muy corto. Por tanto, resulta fundamental que se documente los restos materiales in situ, sin pérdida de tiempo, al objeto de conseguir interpretar y recabar el mayor número posible de datos y evidencias arqueológicas, que permitan efectuar una adecuada interpretación y un acertado análisis histórico.

\section{Descripción del hallazgo}

La fortificación objeto de nuestro trabajo, el Reducto inglés, se localiza sobre la flecha de arena situada entre el Castillo de Sancti Petri y Torregorda, cercana al extremo de la Punta del Boquerón, en la actual playa de Camposoto (San Fernando, Cádiz). Se trata de un paisaje dunar muy activo por la dinámica litoral y la constante exposición a los vientos reinantes en la zona. El origen de estas formaciones geológicas son el aporte de las corrientes dominantes, que provocan un proceso de desplazamiento de las desembocaduras fluviales y de pequeños caños mareales, propiciando al mismo tiempo la creación de zonas de marismas, convertidas en la actualidad en paleomarismas, fácilmente detectable por la aparición de un sustrato de textura gris y arcillosa.

Esta flecha litoral limita al exterior con el océano atlántico y hacia el interior con el Caño de Sancti Petri. Este caño tiene una longitud de $18 \mathrm{~km}$ y se extiende desde el saco interno de la Bahía de Cádiz, lugar donde se ubica el histórico Arsenal de la Carraca, hasta su desembocadura en mar abierto. Su curso comprende una extensa red de caños secundarios conectados que vierten sus aguas en función del ciclo mareal en la amplia zona de marismas que conforman los términos municipales de San Fernando, Puerto Real y Chiclana de la Frontera. Este espacio cuenta en la actualidad con una figura de protección legal, al formar parte del 
Parque Natural Bahía de Cádiz (Ruiz et al., 2005: 86). Desde el punto de vista patrimonial este yacimiento se localiza dentro de la figura de protección Zona de Servidumbre Arqueológica "Bahía de Cádiz" (Orden de 20 de abril de 2009, BOJA 101 de 28 de Mayo de 2009), declarada como tal por la gran cantidad de hallazgos que señalan y evidencian el papel jugado por esta bahía desde época prehistórica hasta contemporánea, y donde se presume la existencia de restos arqueológicos de interés. El área comprende el interior del polígono definido por unos vértices cuyas coordenadas se especifican, y en este caso concreto, el Dominio Público Marítimo Terrestre (DPMT), constituye el límite terrestre de este polígono.

Según los estudios geoarqueológicos realizados sobre la playa de Camposoto, la presencia de un potente nivel de fango bajo la capa de arena de la actual playa muestra claramente que todo ese espacio era, tiempo atrás y aún pendiente de datación, una marisma emergida desarrollada a resguardo de un cordón o flecha litoral que debía situarse en el espacio que hoy ocupa el mar, a una distancia que por el momento no se puede precisar más allá de los últimos dos siglos por el efecto destructivo de la erosión marina sobre la playa (Alonso et al., 2009). Atendiendo a la presencia de los restos de un navío de línea que participó en el combate naval de Trafalgar y que naufragó en esta zona en octubre de 1805, e identificado por el Centro de Arqueología Subacuática como el Fougueux (Izaguirre et al., 2010). Otros autores han llegado a concluir, por la dispersión de la artillería de este buque (González, 2009), que la línea de costa a inicios del siglo XIX estaría situada en la actualidad mar adentro, a unos 400 metros de la orilla actual (Bethencourt et al., 2011: 48).

Las evidencias arqueológicas del antiguo Reducto inglés se localizan en la zona intermareal abierta al mar, a una distancia de unos 1500 metros del extremo de la Punta del Boquerón, como podemos apreciar en este plano general de la Bahía de Cádiz (Figura 1).

Éste se construyó en el frente atlántico de dicha flecha, donde existiría un cordón dunar de vegetación, que estaría presente a principios del siglo XIX, y que sería utilizado para proveerse de material vegetal para la construcción de la fortificación.

En el momento del descubrimiento, lo que se podía contemplar con la bajamar eran los restos antropizados de las antiguas marismas, al descubierto tras la pérdida de la cobertura de arena de playa a causa de los temporales. Como hemos visto con anterioridad, esta paleomarisma es el indicador geomorfológico del retroceso litoral que se constata entre Torregorda y Sancti Petri. En esta área se llevaron a cabo excavaciones por parte del ejército inglés, que se encargó de la construcción del reducto en 1811. El objetivo era abrir zanjas que permitiesen la cimentación de las nuevas estructuras diseñadas por los ingenieros españoles y que formaban parte de las líneas de defensas frente al ejército invasor napoleónico durante el asedio de Cádiz. Estas estructuras, más o menos

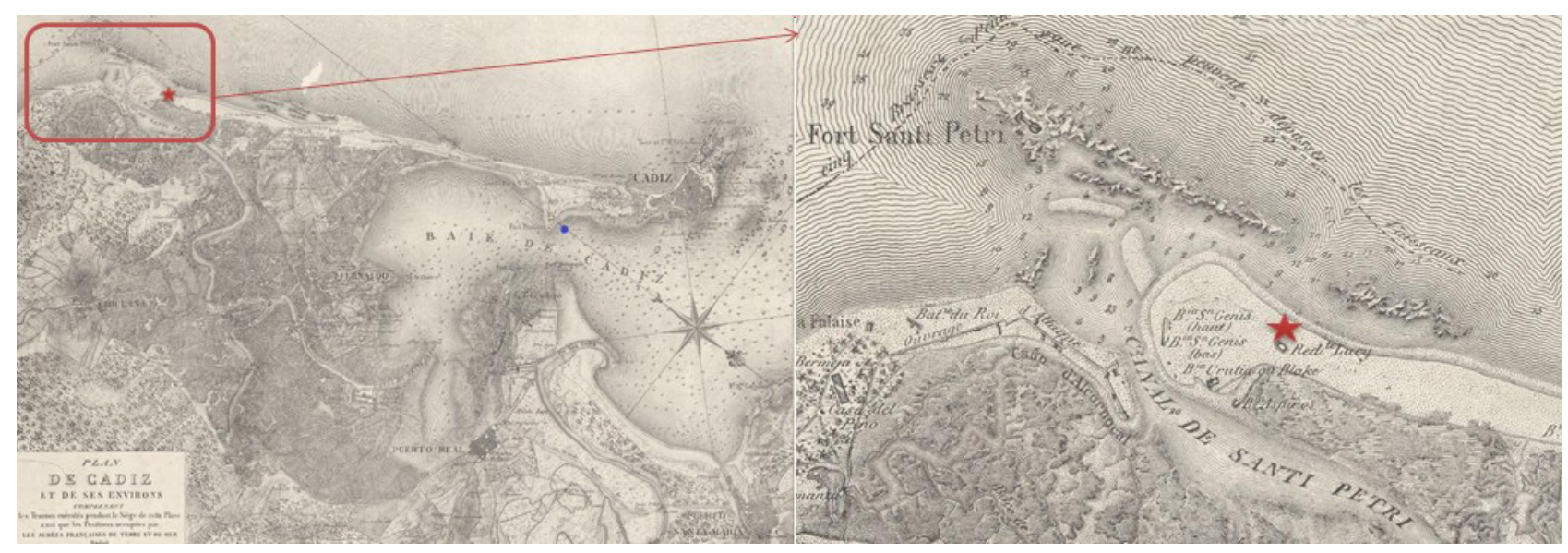

Figura 1. Plan de Cadiz et de ses environs : comprenant les Travaux exécutés pendant le Siége de cette Place ainsi que les Positions occupeés par les Armées Françaises de Terre et de Mer: réduit d'aprés celui levé a l'Echelle du 1/10.000 par les Offrs. du Corps Royal des Ingenieurs. Geoges français dans la Campagne de 1823 Cádiz (Bahía). Imprimerie Litographie de G. Engelmann ed, [1823?].

(Fuente: Gallica, Biblioteca Nacional Francia). 
efímeras, se construían acopiando arena, fango y otros materiales para reforzar el parapeto que serviría para camuflar las piezas de artillería. Para evitar el deslizamiento de los materiales se utilizaban estacas de madera que reforzaban la estructura resultante.

En la visita que efectuamos, acompañados del técnico A. Sáez pocos días después del hallazgo, fue posible comprobar el efecto de la dinámica mareal sobre los restos que se conservaban del reducto, tras el paso de más de doscientos años. Sobre el terreno y en el lugar del hallazgo, en algunas partes, las líneas rectas y los ángulos ayudaban a interpretar los ya escasos restos visibles. El conjunto de las improntas visualizadas en un primer momento, $\mathrm{y}$ cuya imagen puede verse a continuación (Figura 2 ), se aterró en un corto espacio de tiempo, no permitiendo tomar suficientes puntos con el GPS que diesen opción a levantar un croquis completo del perímetro exterior, y a partir de ahí cotejar esos datos con el plano existente del reducto.

Los trabajos de esta visita consistieron en realizar la correspondiente documentación gráfica y su posicionamiento con coordenadas que georreferenciasen algunos puntos de la estructura que aún se conservaban. Se tomaron además algunas medidas que sirviesen para intentar comparar los restos localizados con la documentación planimétrica existente de las antiguas fortificaciones levantadas en toda la zona de Camposoto.

Al tratar de poner en relación los puntos de coordenadas obtenidos sobre el terreno con la planimetría del reducto, llegamos a la conclusión de que no era posible llevar a cabo esa identificación. Los ángulos que se reconocían claramente en las primeras imágenes del reducto ya habían desaparecido en la segunda ocasión que se observaron los restos.

Teniendo presente que las evidencias conservadas eran sólo trazas y que la altura del nivel de fangos era mínima, resultó imposible identificar los restos, únicamente a través de las huellas en la arena, con la estructura militar a la que debe corresponderse. Sin embargo, está claro que existe una intencionalidad constructiva en las evidencias documentadas, tanto por la linealidad de los cortes de la arcilla y los ángulos de algunas esquinas que se conservaron, como por la utilización de estacas distribuidas de manera regular, buscando una funcionalidad específica, así como la evidencia de restos orgánicos acumulados en determinadas zonas.

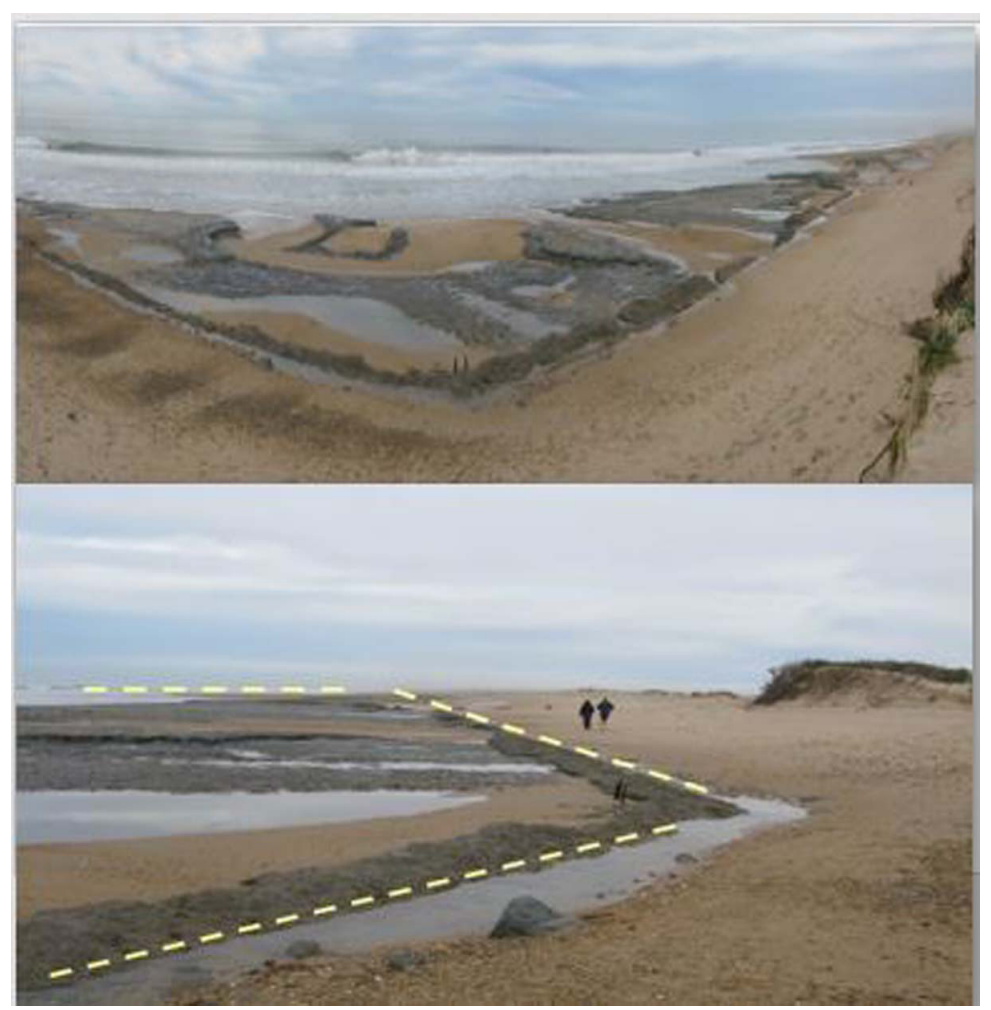

Figura 2. Dos perspectivas de las improntas conservadas del reducto. (Fuente: A. Sáez). 
En varios puntos se conservaban testigos de las estacas que se utilizaron para su construcción. Incluso fue posible intuir la presencia de algunos postes de madera en la zona interna del reducto, que servirían de soporte para algunas dependencias levantadas dentro del complejo fortificado, con la intención de servir de resguardo a la tropa o como depósito de armas o pólvora. Así mismo, se pudo constatar, en algunas zonas de acumulación de arcillas, gran cantidad de restos vegetales, que guardarían relación directa con los materiales constructivos originales que conformarían la estructura del reducto, ya que estos se construían utilizando para reforzar los parapetos con cestos de mimbre y elementos de fibra vegetal trenzados, para dotar a la estructura resultante de una mayor consistencia (Figura 3).

Las medidas tomadas sobre el terreno de lo que se conservaba, podrían coincidir, grosso modo, con las que se representan en la documentación planimétrica del Reducto inglés, teniendo presente que la acción del mar ha ido erosionando las arcillas (material relativamente blando), y que todo el frontal marítimo se encuentra muy alterado. Por este motivo la estructura ha perdido prácticamente su fisonomía original. Sí fue posible seguir el trazado exterior de la efímera fortificación en la parte este, más protegida de las acciones del mar.

Se han localizado y documentado en el espacio interior del recinto militar un par de estructuras rectangulares de alrededor de 1x1 metro, excavadas a la misma cota que la cimentación del reducto y que conservan una profundidad de alrededor de $25 \mathrm{~cm}$. Tres estructuras idénticas se han documentado también, en la misma línea de costa, a una distancia de 1,5 km en dirección norte. Desconocemos si pudieron tener un uso asociado al establecimiento militar, al carecer de otros elementos de juicio. Puede también plantearse que guarden algún tipo de relación con la habitual extracción, mediante el uso de maquinaria retroexcavadora, de proyectiles modernos, que esporádicamente aparecen en la zona, que hasta la década de los noventa tuvo un uso militar, concretamente era la línea de tiro del Polígono Militar de Experiencias de Costa Costilla y el de González Hontoria, pertenecientes al Ministerio de Defensa.

La ubicación de los restos del reducto inglés documentados, a pesar de algunos cambios apreciables en un espacio físico en continua evolución como es la flecha de Sancti Petri, guardan relación con las otras defensas construidas en esta zona: Batería de Urrutia, Aspiroz y San Genís. Con respecto al resto de las fortificaciones levantadas en la Punta del Boquerón, las distancias entre las fortificaciones serían las siguientes, tomadas desde el centro aproximado del Reducto inglés:

- A la batería de Aspiroz: 530 metros.

- A la batería de Urrutia: 610 metros.

- A la batería de San Genís: 855 metros.

\section{Su representación en la cartografía histórica}

La Bahía de Cádiz cuenta, por su importancia geoestratégica, con una abundante cartografía histórica de su territorio. A partir del siglo XVIII comienzan a ser representaciones bastante fidedignas por los avances científicos de la Ilustración. Su análisis diacrónico permite conocer la transformación del medio físico (Márquez et al., 2016), así como la evolución morfológica de la parte emergida y sumergida de este marco geográfico. Sin embargo, a pesar de la existencia de abundante cartografía histórica de la Bahía gaditana, son escasos los mapas en los que es posible localizar la posición del Reducto inglés en la zona de la Punta del Boquerón. Los enumeramos y describimos a continuación:

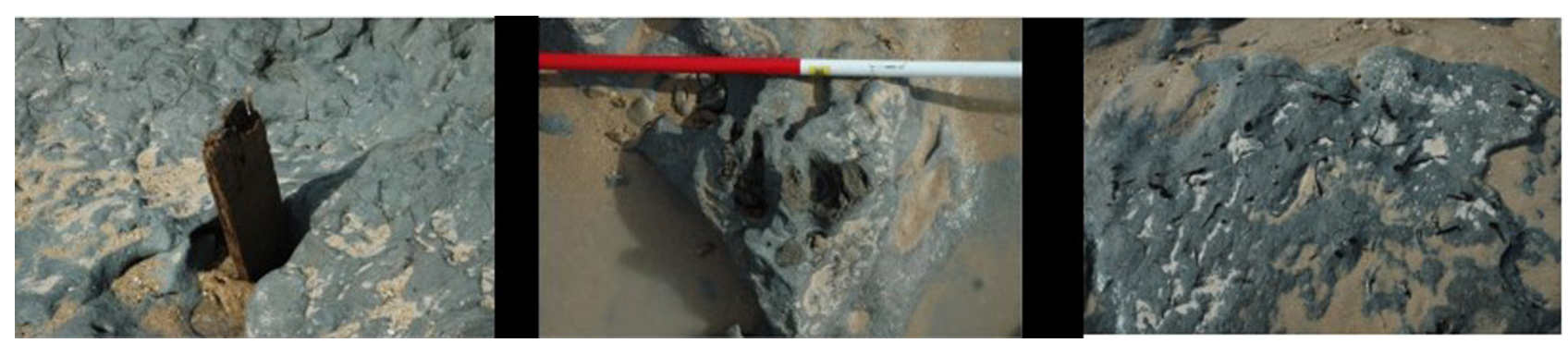

Figura 3. Poste de madera y restos de materiales orgánicos utilizados para la construcción del reducto. (Fuente: Fondo gráfico CAS IAPH). 
1. Planimetría del Reducto inglés incluida en la obra realizada por Carlos Vargas Machuca. Lámina 44 (Sánchez, 2004). Esta lámina representa, además de la planta, los alzados, con dos vistas de las secciones (Figura 4). A Vargas-Machuca, como militar perteneciente al Real Cuerpo de Ingenieros del ejército español, se le encargó confeccionar un inventario de las distintas fortificaciones que conformaban el sistema defensivo de la Isla de León, actual San Fernando, que analizaremos con posterioridad, incluyendo además datos concernientes a sus características técnicas. Se trata de una obra manuscrita, firmada y fechada en 1814 por el autor, realizada con la técnica a plumilla en tinta negra y coloreada a la acuarela en azul, verde, rojo y ocre.

2. Plan de Cadiz et de ses environs : comprenant les Travaux exécutés pendant le Siége de cette Place ainsi que les Positions occupeés par les Armées Françaises de Terre et de Mer: réduit d'aprés celui levé a l'Echelle du 1/10.000 par les Offrs. du Corps Royal des Ingrs. Geoges. Français dans la Campagne de 1823 Cádiz (Bahía). Imprimerie Litographie de G. Engelmann ed, [1823?]. En este registro tenemos una vista general de la localización del Reducto de Lacy en la Bahía de Cádiz (Figura 1).

Es posible apreciar en este mapa, y con mucho detalle de factura, el aspecto defensivo que presentaba esta zona de la Punta del Boquerón. Aparecen representadas las Baterías de San Genís, Urrutia o Blake (como aparece en la leyenda), la de Aspiroz, y por último el ya rebautizado como Reducto de Lacy. Hay que decir que Blake fue uno de los generales ingleses destinados a Cádiz para contrarrestar el ataque de las tropas francesas. Frente a la fortificación que nos ocupa se distingue perfectamente la línea de arrecifes, donde se aprecia un ligero entrante en la línea de costa frente al reducto, que podría ser ya un indicador de la pérdida de sedimento en el área por el avance del mar.

3. Plan de l'attaque de l'ille de Leen dirigés per l'embocuchure du Sn. Petri. 1823 (Pérez, 1978: 512). Realizado, según consta en la leyenda, por el cuerpo de ingenieros del Ejército del Pirineo. El reducto aparece representado en el frente atlántico de la flecha litoral, y por lo tanto, muy expuesto a la acción del oleaje y también a la fuerte influencia de los vientos típicos de esta costa, lo cual explicaría su acelerado estado de degradación, junto con el carácter efímero del material vegetal empleado para su construcción. Se puede apreciar en el detalle de la cartografía que en el conjunto defensivo aparecen representadas en la zona las Baterías de San Genís, Urrutia, Aspiroz, y un pequeño croquis de la planta del reducto que nos ocupa con una leyenda claramente legible: "Fort des Anglois", (Fuerte de los Ingleses). Estas otras fortificaciones fueron levantadas con anterioridad al Sitio de Cádiz, y se hallaban construidas con material de cantería, lo que ha permitido que se conserven en la actualidad (Figura 5).

4. Mapa de los alrededores de Cadiz /Dufour, Auguste-Henri (1798-1865). [s.l.][s.n.], 1839. Bibliothèque nationale de France, département Cartes et plans, GEC-2534. ark:/12148/btv1b530296275. En este documento cartográfico, entre otros datos, aparecen representadas todas las baterías y reductos de Cádiz y San Fernando. Entre ellos, los situados en el eje norte sur desde Torregorda a Sancti Petri: Batería de la Libertad Cívica, Batería del Rey Constitucional, Batería de la Independencia, y por supuesto en el extremo del istmo, denominado actualmente punta del Boquerón, el Re-

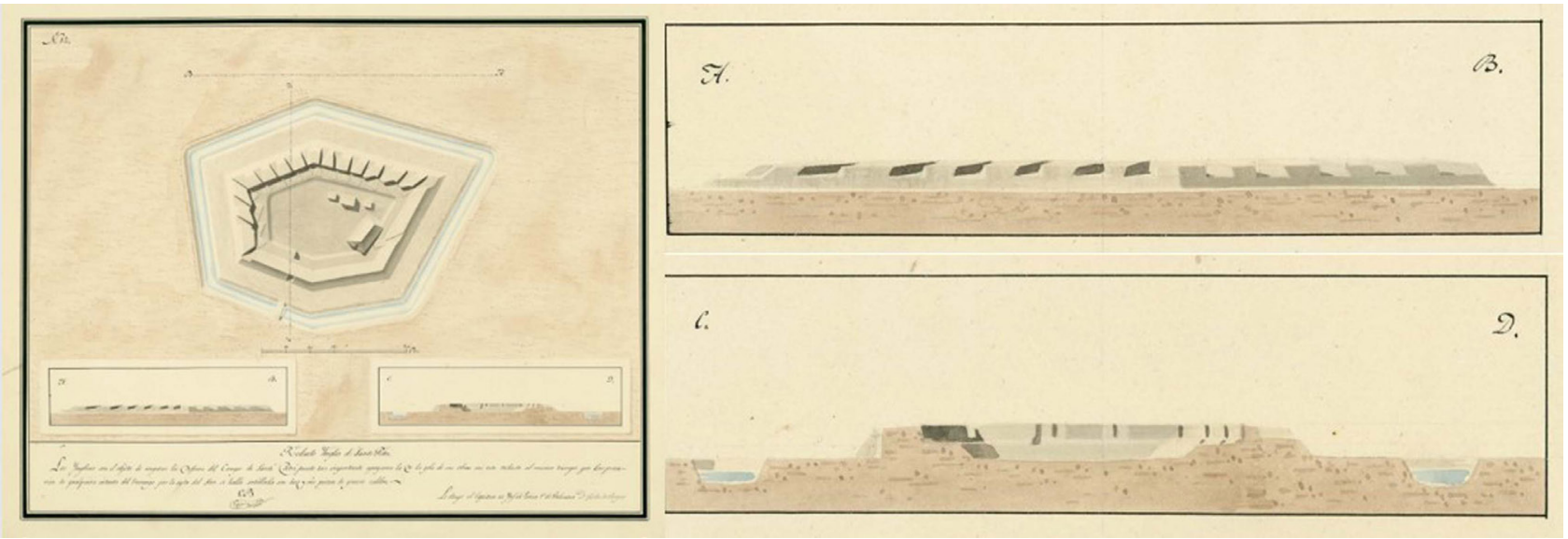

Figura 4. Plano y alzados del Reducto Inglés. (Fuente: Vargas Machuca). 


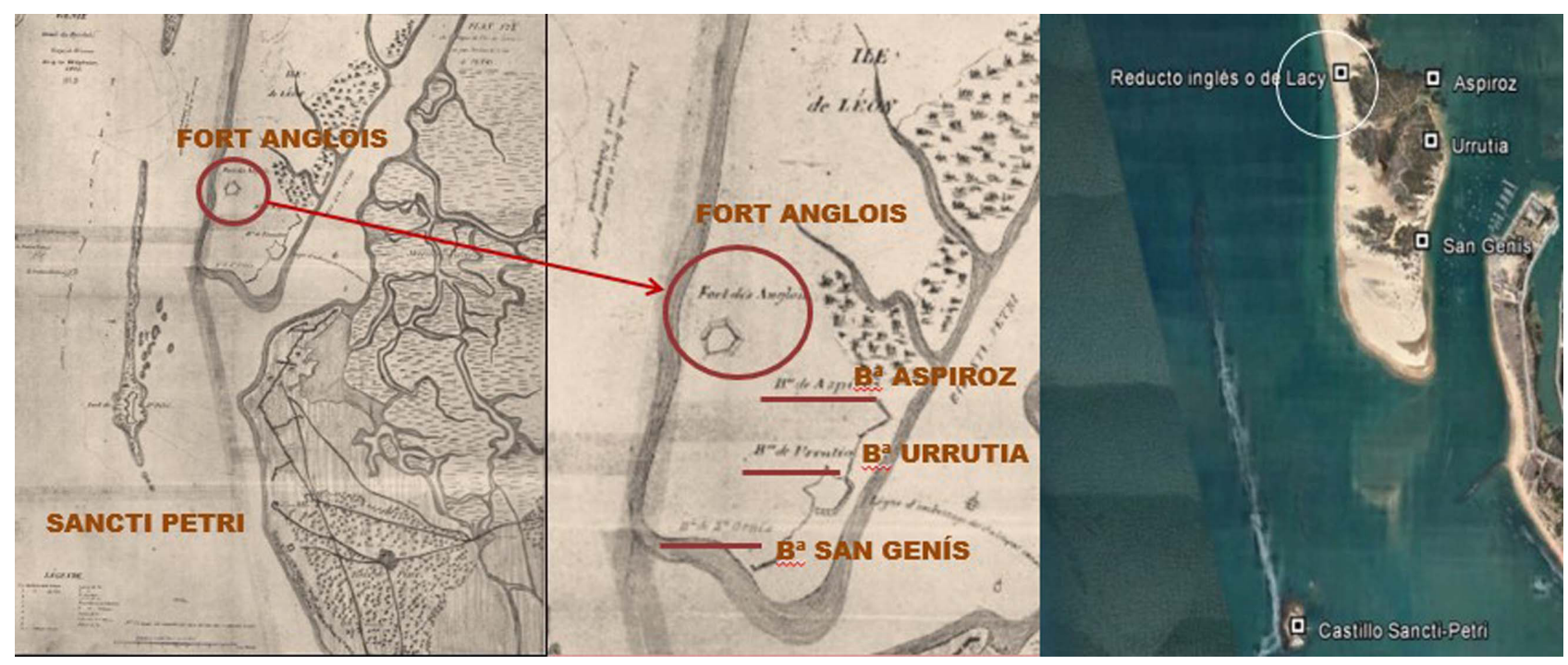

Figura 5. Plano de 1823 con la ubicación del reducto y su relación con otras fortificaciones de la Punta del Boquerón. (Fuente: Google Earth).

ducto de Lacy (anterior Reducto inglés), así como las Baterías de San Genís, Urrutia y Aspiroz. Los nombres dados a estas fortificaciones denotaban claramente la ansiada libertad por la que tanto había luchado el pueblo de Cádiz y algunos militares constitucionales, entre ellos el general Lacy, como veremos posteriormente.

\section{Contextualización histórica}

La construcción de la fortificación costera denominada Reducto inglés o de Lacy se encuadra históricamente en el marco de la Guerra de la Independencia de España contra el invasor francés (1808-1814), bajo la soberanía de Napoleón, que siguiendo su política de expansión europea, necesitaba la alianza de España. Su estrategia inicial era hacerse, mediante la diplomacia y los "Pactos de Familia", con el gobierno del país vecino y con el poder naval de su armada. Éste era un elemento fundamental en sus planes para obtener el control de los mares y permitir su gran objetivo: la invasión de Inglaterra.

La derrota y pérdida de gran número de efectivos navales a consecuencia de la Batalla de Trafalgar en 1805 (Gallardo, 2005), supuso un gran revés para sus ambiciones, imposibilitando el desarrollo de las operaciones marítimas y la ansiada invasión. Es por ello que el esfuerzo de Bonaparte debió centrase en alcanzar el dominio terrestre de Europa, incluida España.

Las abdicaciones de Bayona supusieron, como consecuencia, la llegada al trono de España de
José I, hermano de Napoleón Bonaparte, y la consiguiente caída de Carlos IV y su hijo Fernando VII, así como la entrada de un gran contingente del ejército francés en territorio español. Este hecho propiciaría el alzamiento popular materializado en el "Dos de Mayo" en Madrid y el posterior alzamiento general de la nación contra el nuevo rey francés. En todo el territorio español se produciría un paulatino rechazo contra el invasor francés por los excesos que cometieron, entrando en muchas ciudades a sangre y fuego e infringiendo graves saqueos, como el de Córdoba, así como delitos de violaciones y asesinatos de la población civil. De hecho, en 1808, se iniciaría con el levantamiento nacional, la Guerra de la Independencia, que se dilataría en el tiempo hasta 1814. Este período de siete años supuso una grave caída de la economía del país, afectando por supuesto a la Bahía de Cádiz y a sus operaciones del comercio de ultramar, muy mermado de por sí ya, con el decreto del Libre Comercio de 1778 y con las Guerras navales entre las potencias a escala mundial de España, Francia e Inglaterra.

Mientras se sucedían los primeros hechos de la Guerra de la Independencia, en la Bahía de Cádiz continuaba fondeada la escuadra de Rosily, con cinco navíos y una fragata, restos de la escuadra superviviente del combate Trafalgar, y que fue rendida en junio de 1808 en la Batalla de la Poza de Santa Isabel por las fuerzas militares españolas. Se trataba del primer conflicto armado de la marina de España contra las tropas invasoras de Napoleón Bonaparte, que tuvo lugar un mes antes 
de la derrota del general Dupont en Bailen en el mes de julio, en su intento por invadir Andalucía (Márquez, 2008).

Frente al avance hacia el sur de España de las tropas del ejército francés de Midi para la invasión de Andalucía, al mando de Dupont, la Junta Central de Regencia se vio obligada a abandonar Sevilla y a trasladarse a la Isla de León (San Fernando), estando ya instalada allí a principios de 1810.

La elección de la Bahía de Cádiz, como un lugar seguro, fue recomendada por el teniente general de la Armada Antonio Escaño, elegido en 1810 miembro del Consejo de Regencia de España e Indias. Este experimentado marino, excombatiente de Trafalgar, conocía perfectamente las posibilidades geoestratégicas de la bahía para la defensa de ese gobierno provisional y de toda la población de Cádiz, teniendo en cuenta que podría convertirse, como así fue, en el último bastión del territorio nacional.

Dos de los enfrentamientos destacables que tuvieron lugar contra el ejército invasor, posicionado desde Rota hasta el Caño de Sancti Petri, fue la toma de Matagorda en 1810 (Izco, 2012) y la Batalla de Chiclana en 1811 (Durán, 2012). A pesar de ganarse este segundo enfrentamiento, se trató de un intento fallido del ejército aliado anglo español, apoyado por unidades portuguesas, de poner fin, de manera definitiva, al asedio de Cádiz. Éste se prolongó durante dos años, en un desesperado e inútil esfuerzo de las tropas napoleónicas por tomar el control de la plaza fuerte de Cádiz.

En un documento interceptado a los militares franceses por el "Cuarto Ejército Español" se muestra la desesperanza de un oficial del cuerpo de ingenieros del ejército napoleónico, que estuvo presente en las operaciones de bloqueo de Cádiz desde la Isla del Trocadero (Puerto Real). Este militar dirigía el batallón del cuerpo de ingenieros, destinados en la Bahía de Cádiz, para ayudar a sus tropas de infantería en la conquista de este territorio. Está firmado en la población gaditana de Puerto Real con fecha 26 de marzo de 1811 y se conserva en el Archivo Histórico Nacional (Márquez, 2015: 85-96).

El general de brigada Maríe Théodore Garbé, dirigió un informe al coronel del cuerpo de Ingenieros Lejeune, para que le comunicase la situación en el país. Pero este documento, firmado con el título "Notes sur le Siege de Cadix", fue interceptado y requisado en Toledo el 6 de abril. Se trata de un informe técnico sobre cómo ejecutar un asalto a la ciudad de Cádiz. En la misiva se cuestionaba entre otros aspectos, la eficacia de tiro de las famosas piezas de artillería "Villantroys". Estas piezas de artillería, traídas para doblegar mediante disparos de gran alcance al pueblo de Cádiz, fueron expresamente fundidas en la Fábrica de Artillería de Sevilla.

La situación del ejército sitiador no era tan buena como cabría esperar, ya que Cádiz tenía garantizado el abastecimiento por vía marítima, contando con todo el apoyo y la infraestructura de la Royal Navy. Se dio la paradoja de que los sitiadores tenían más escasez de recursos que los propios sitiados. Esa situación es la que denuncia el ingeniero Garbé en su informe. Llega también a la conclusión, después de tan ineficaz asedio, de que era más fácil conseguir el objetivo diseñando un ataque por tierra a la Isla de León. Planteaba que una vez traspasadas tropas de infantería a este lugar, avanzarían desde allí hacia la plaza de Cádiz. Ese fue su dictamen, asegurando el éxito de la empresa. Su planteamiento, consciente de la importancia estratégica de esta zona, era efectuar un ataque conjunto al enemigo por tres puntos simultáneamente: Puntales, Puente Suazo e Isla de León por la parte de Caño de Sancti Petri (Márquez, 2015: 85-96). Pero su plan nunca llegó a ejecutarse, aunque queda la duda de que, si sus inmediatos superiores hubiesen podido analizar su propuesta táctica y lo hubiesen llevado a cabo, la plaza gaditana hubiese pasado, tal como deseaba Napoleón, a ser territorio francés.

El asedio a la ciudad de Cádiz tendría su fin en 1812, con el abandono de la Bahía gaditana del ejército invasor, que durante dos años estuvo inútilmente intentando tomar el control de la única ciudad que no reconocía al nuevo rey francés José I, y donde se resguardaba el gobierno provisional de la nación. Dos años después, en 1814, finalizaría la Guerra de la Independencia de España, restaurándose la monarquía borbónica en la persona de Fernando VII, que juró la Constitución Liberal nacida en Cádiz el 19 de marzo de 1812 de la mano de los diputados de las Cortes Generales españolas. Sin embargo, el rey no cumplió su palabra, volviendo a imponer su poder absoluto a su regreso a España al derogar las cortes en 1814, rechazando la soberanía de la nación y otros apartados liberales de esta constitución inspirada en la francesa, restableciendo todas las instituciones del Antiguo Régimen. En paralelo, fueron arrestados muchos miembros de la oposición, tanto militares como civiles. 
Muchos de los militares liberales que lucharon por la vuelta a España del rey borbónico, "el deseado", como así se le denominó durante la invasión napoleónica, se vieron nuevamente defraudados ante la traición del monarca español, y algunos de ellos promovieron posteriormente una revuelta para hacer cumplir a Fernando VII lo pactado: juramento de la Constitución de 1812 y abolición del Tribunal de la Santa Inquisición. Este período que siguió al "Sexenio Absolutista" (1814-1820) es conocido como el "Trienio Liberal" o "Trienio Constitucional" (1820 y 1823). Varias conspiraciones de militares constitucionales consiguieron establecer un gobierno de carácter liberal durante ese corto período. Sería en concreto el "Pronunciamiento del Coronel Riego" en Las Cabezas de San Juan (Sevilla), donde se obligó al rey "traidor" a acatar la Constitución, decretar una amnistía y convocar elecciones.

Este periodo no tendría finalmente éxito y el rey Luis XVIII de Francia, de la dinastía borbónica, decidió entonces atender la petición de auxilio de su sobrino español, Fernando VII. Esa ayuda se materializaría con el envío el 3 de abril de 1823 de un contingente militar de 100.000 hombres al mando del duque de Angulema, los denominados "Cien mil hijos de San Luis".

Refugiado el gobierno liberal nuevamente en Cádiz, tras verse obligado a abandonar Sevilla, mantenían como rehén al monarca. La bahía gaditana sufriría un segundo asedio una vez llegadas a destino las tropas francesas, siendo bombardeada de nuevo como en 1810. Uno de los puntos de defensa de Cádiz y de San Fernando sería la zona del Caño de Sancti Petri. Una vez más, habría que recurrir a volver a poner en uso el sistema de defensas diseñado para salvaguardar la plaza gaditana y la Isla de León durante la Guerra de la Independencia.

Si bien la resistencia de los liberales fue enérgica, los franceses acabarían con el control del fuerte del Trocadero (Puerto Real). Otro de los enfrentamientos por obtener el control de puntos estratégicos en la Bahía de Cádiz se produjo en el castillo de Sancti Petri. En este caso, fue un pequeño enfrentamiento naval en el que participaron tres fragatas de la armada francesa: La Guerrière, Le Centaure y Le Trident. La superioridad numérica, 450 soldados franceses frente 150 soldados españoles que defendían el castillo, hizo que se rindieran sin condiciones (Calatrava, 2014). Este combate naval que acabó con la derrota del ejército constitucio- nal español en Sancti Petri el 20 de septiembre de 1823 aparece representado en un grabado de la época (Figura 6).

Finalmente, la ciudad de Cádiz y el ejército constitucionalista se rindieron con la condición de que Fernando VII prometiese la libertad de la Constitución de 1812, pacto que fue finalmente incumplido en cuanto fue liberado, dando fin a todas las medidas impuestas por el Trienio Liberal el 1 de octubre de 1823.

\section{Plan de defensa de la Isla de León durante la Guerra de la Independencia de España}

A finales de enero de 1810 el ejército de Extremadura, al mando del duque de Alburquerque, se dirigió hacia la Isla de León y Cádiz, lugar donde se había refugiado la Junta Provisional del Gobierno de la nación. Mientras, el mariscal francés Víctor había conseguido la rendición de varias ciudades andaluzas, entre ellas Córdoba y Sevilla. En esta segunda ocasión no sucedió como en la Batalla de Bailen en 1808, ya que las tropas francesas consiguieron traspasar Despeñaperros e invadir Andalucía. Su próximo objetivo era dirigirse a la Bahía de Cádiz para tomar el control, pero el duque de Alburquerque, llegado el 4 de febrero de 1810 a la Isla, había dispuesto ya las medidas oportunas para su defensa, impidiéndole el paso al cortar el acceso por el puente de Suazo. Al día siguiente, y muy cerca de ese puente, tuvo lugar la Batalla del Portazgo, como se denominó al enfrentamiento entre ambos ejércitos en la única zona que daba acceso por tierra a San Fernando y Cádiz. Esa fecha, 5 de febrero de 1810 , marca el inicio del asedio del ejército francés napoleónico, un contingente de sesenta mil hombres, al mando del Mariscal Víctor y que duraría dos años, hasta el 24 de agosto de 1812.

Tanto Cádiz como la Isla de León se prepararon para resistir el ataque, pero contrariamente a lo que había sucedido siempre, esta vez la invasión venía del frente de tierra y no por vía marítima.

La Bahía de Cádiz contaba con una pieza fundamental para su salvaguarda, la lámina de agua que separaba Cádiz y San Fernando del continente. La rada gaditana, el caño de Sancti Petri y las zonas de marismas constituyeron una línea de defensa natural desde Rota hasta Chiclana. Era una de las pocas ocasiones en las que el enemigo se presentaba por el frente de tierra y no infringía su ataque por mar. La razón, como sabemos, es que Francia había perdido gran parte de sus efectivos navales 


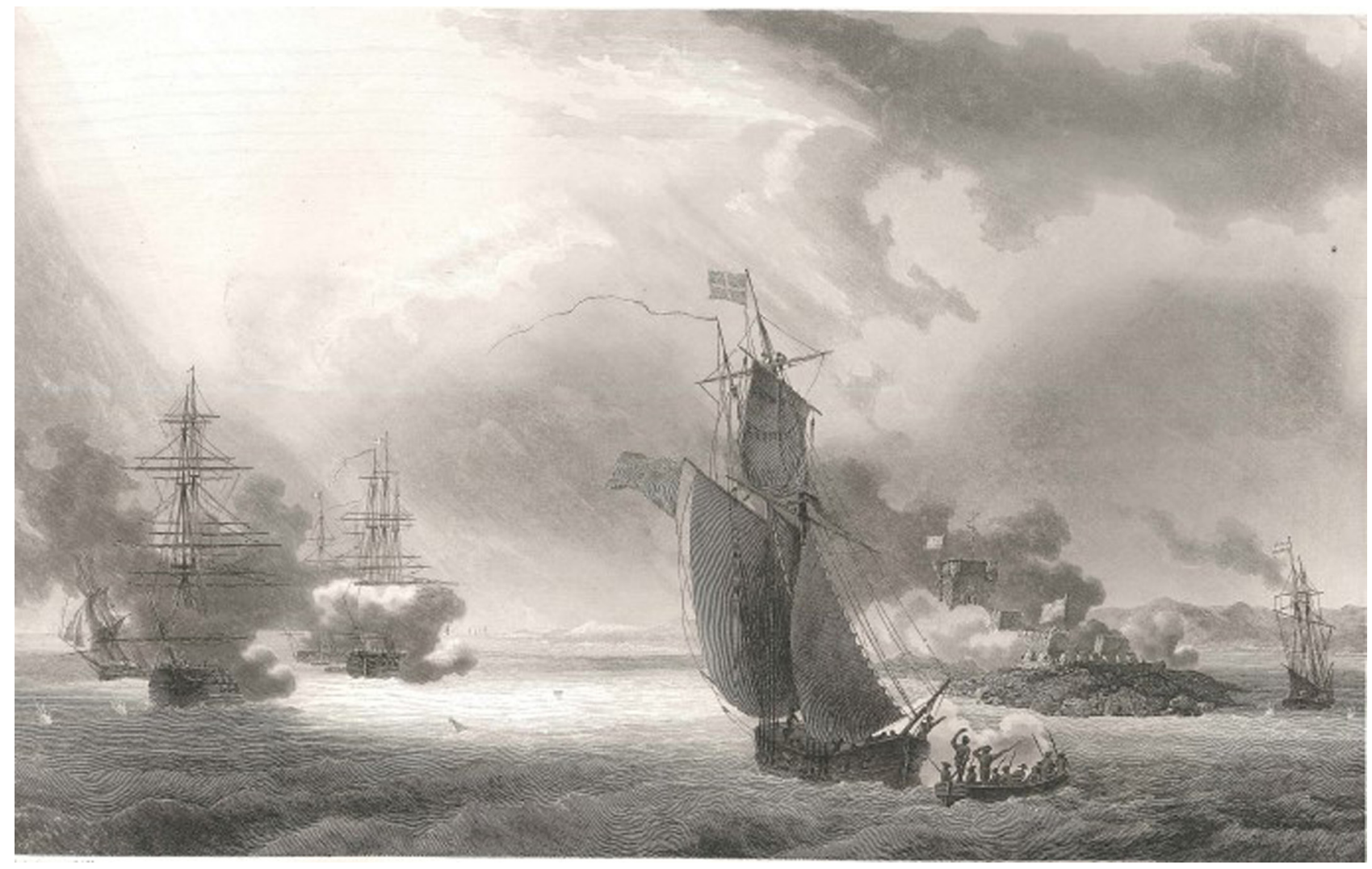

Figura 6. Grabado Prise Fort de Sancti Petri, 1823. (Fuente: Gravure Versailles).

cinco años antes, a consecuencia del desastre naval de Trafalgar y del temporal que aconteció los días posteriores.

Para ello se creó un plan de defensa de todo el territorio en el que, por un lado, se inutilizaron fortificaciones que pudiesen ser tomadas por el enemigo (como sucedió con las emplazadas en la costa de Rota, El Puerto de Santa María, Puerto Real y Chiclana), entre ellas el castillo de Santa Catalina de El Puerto de Santa María, destruido por el navío inglés Milford (Márquez, 2020: 112), mientras que, por otro, se reforzaron las ya existentes en San Fernando y Cádiz. Además, se decidió la construcción de una serie de baterías y reductos provisionales para reforzar, en las zonas más débiles, el sistema defensivo. Este fue el caso del extremo sur de la lengua de arena que se extendía desde Cádiz hasta el castillo de Sancti Petri.

La protección de esta zona era vital para impedir un asalto por el frente de tierra a la ciudad de Cádiz dado que, si el enemigo desembarcaba por esa zona de la playa (lo cual era factible en unas condiciones meteorológicas favorables), podría atacar sin obstáculos tanto esta ciudad como la población de San Fernando.

El complejo defensivo del área de Sancti Petri, tanto por la zona interior del caño como por el frente de la playa de Camposoto, estaba formado por el eje que integraba el Castillo de Sancti Petri y las baterías de Urrutia, Aspiroz y San Genís. Constituían la primera línea de defensa para contrarrestar el ataque de las tropas napoleónicas por la zona sur del istmo de Cádiz. De éstas las realizadas con materiales de cantería y por tanto más sólidas, eran las de Sancti Petri y Urrutia.

La batería de San Genís se construyó en el año 1811, al igual que el Reducto inglés de Sancti Petri, con materiales efímeros como fango y fajinas. Este último material estaba formado por un haz de ramas delgadas muy apretadas. Esta fortificación tenía una capacidad para 30 piezas de artillería, y fue levantada en sustitución de otra existente de escasa altura, llamada La Vieja. También se reutilizó en esta misma línea, el Reducto inglés, para dar servicio en 1823 durante el asalto de los "Cien mil hijos de San Luis," siendo artillada con 5 piezas (Martínez, 1975: 118). Asimismo, la Batería de Aspiroz, construida también en 1811 con materiales efímeros, montaba 5 cañones. Se situaba al pie del Caño de Sancti Petri, a la izquierda de la Batería de Urrutia (Martínez, 1975: 120-121). 
La Punta del Boquerón constituía otros de los caminos de acceso a Cádiz, en este caso desde Chiclana de la Frontera, cruzando el caño de Sancti Petri con una barca de pasaje para luego proseguir el camino del arrecife en dirección a la ciudad. El derecho de explotación de su uso dependía, desde hacía siglos, de la casa ducal de Medina Sidonia. Durante la guerra de la Independencia controlar este acceso era vital para traspasar tropas amigas a la capital e impedir, como así sucedió, el paso del ejército enemigo cuando se estableció el sitio de Cádiz por los franceses.

Durante este período se construyó para ello, como constatamos a través de un plano de la época de la Bahía de Cádiz, un puente de barcas denominado "temporary bridge" (Smith, 1813). Curiosamente en este mapa fechado en 1813 no aparece representada en el istmo norte de la isla de Cádiz el Reducto inglés, a pesar de tener detalladas todas las baterías y reductos existentes en la bahía gaditana. Su levantamiento viene explicado por el título del mismo: intentar hacer un estado de las fortificaciones y reductos que los ingleses y españoles tenían a su disposición. En la zona objeto de nuestro estudio, que aparece denominada como "Saint Peter point", sólo aparecen dibujadas las baterías de la zona colindante al caño de Sancti Petri, entre ellas, la batería de
Urrutia. Aunque no se menciona el nombre en la leyenda, si contamos con el dato de los cañones disponibles en la misma, que eran un total de 12 piezas. La que parece corresponder con la Batería de San Genís, contaría con una fuerza artillera de un total de16 cañones y morteros. Esta comunicación temporal fue construida durante el gobierno militar en la Isla de León de José Zayas, al objeto de facilitar el paso de las tropas del general Lapeña. El intento de cruzarlo, por parte de las tropas francesas, obligó a las fuerzas españolas a destruirlo.

El hecho de que el Reducto inglés no parezca ubicado, así como tampoco el de otras fortificaciones en la parte del frente de mar de la actual playa de Camposoto, indica que este plano fue levantado con anterioridad a la articulación del plan de defensa de la Isla por parte de Vargas Machuca, y por tanto, anterior a la consiguiente construcción de baterías y reductos en el área (Figura 7).

De este modo, volviendo a poner en activo esas baterías, quedaba defendido el eje sur que tanto preocupaba por una posible invasión de las tropas francesas por el frente de tierra, tanto en el período de la Guerra de la Independencia como durante el fin del Trienio Liberal.

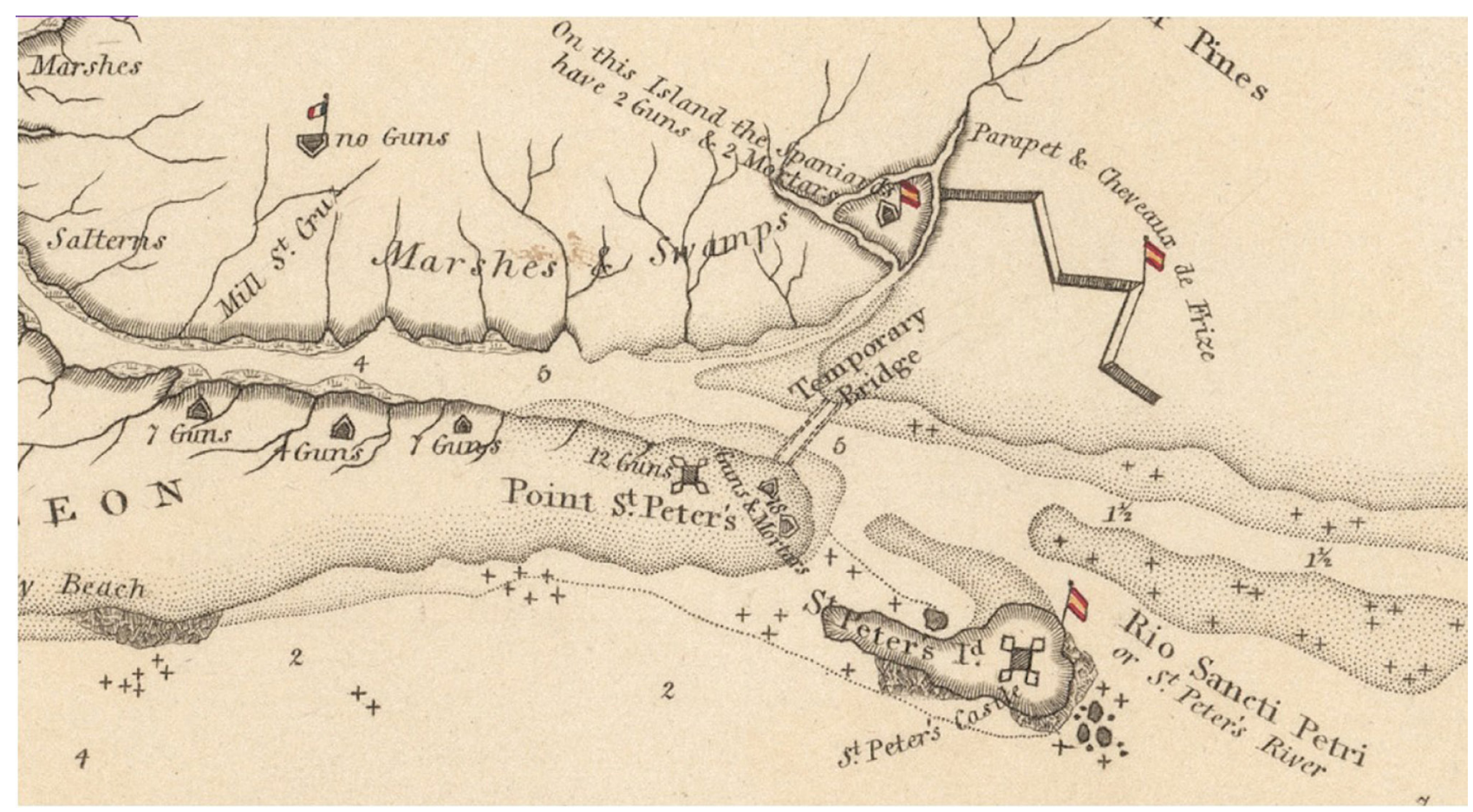

Figura 7. Detalle Plan of the bay and harbour of Cadiz: exhiviting the state of the forts... de William Henry Smith, 1813. (Fuente: Institut Cartogràfic de Catalunya). 


\section{El Reducto inglés del campo de Sancti Petri o de Lacy}

La Isla de León contaba con un total de 22 reductos, que formaban parte de la $1^{\underline{a}}$ y $2^{\underline{a}}$ de las tres líneas defensivas aliadas hispano-británicas contra el asedio impuesto por el ejército napoleónico entre los años 1810 y 1812 (Milán, s.d.).

El reducto que nos ocupa formaba parte de esa 1a Línea de Defensa y contamos con información de su planta y alzado, como vimos anteriormente, a partir de un plano del ingeniero militar Carlos Vargas Machuca (Sancho, 2004: 149), dentro del bloque denominada "Atlas de la Derecha de $1^{\underline{a}}$ y $2^{2}$ a línea. Isla de León", fechado en enero de 1813, compuesto por un total de 20 planos sin numerar.

La llegada de Vargas-Machuca a la Isla de León en pleno asedio francés, se produjo en calidad de soldado voluntario para apoyar con sus conocimientos las labores de defensa de la Isla de León, levantando fortificaciones y realizado un detallado plan de protección, consolidando las fortificaciones existentes y diseñando las que había que levantar de nueva planta (Sancho, 2004: 39), para no dejar ningún punto ciego.

La estrategia planteada por el cuerpo de ingenieros militares españoles e ingleses para impedir el acceso de las tropas francesas y de su artillería, fue contar al mismo tiempo con las defensas naturales del propio paisaje (Caño de Sancti Petri y zona de marismas), y por otro, la construcción en tiempo récord de fortificaciones -reductos y baterías- para los puntos más inseguros, sobre todo terrestres, protegiendo además ciertos lugares que pudiesen dejar expedito el paso por mar de destacamentos militares transportados por embarcaciones menores. Por ello, si bien Francia no disponía de navíos de línea para infringir un gran asedio por mar y su ejército había llegado a pie desde el norte de España, se necesitaba defender esa parte sur del litoral gaditano para prevenir un posible ataque, a pequeña escala, con las lanchas cañoneras construidas por el ejército francés. Es en esta realidad en la que se acometen los trabajos para la construcción del Reducto inglés en la denominada Punta del Boquerón, además de otras baterías en la flecha litoral de Camposoto con este objetivo de defender la zona de un supuesto ataque por mar. Vargas-Machuca las denominó: Rey Constitucional, Independencia, o Intrépidos, ésta última junto a los polvorines de la Marquina o Camposoto (Sancho, 2004: 47).
En la colección de "La Guerra de la Independencia a través de los fondos del Archivo Histórico Nacional" en el Portal PARES hemos localizado un interesante documento que traducía al castellano la valoración realizada en 1811 de un ingeniero militar inglés, el Teniente General Graham, vencedor de las tropas francesas en la Batalla de la Barrosa. Su título es Traducción al castellano de la propuesta hecha el 10 de mayo de 1811 por el teniente general Graham, del Cuerpo de Ingenieros del Ejército británico, para mejorar las fortificaciones de la línea defensiva en torno a Cádiz, particularmente las que cubren el recinto del arsenal de La Carraca, Puente Suazo, Portazgo y Sancti Petri.

Es de suponer por lo anteriormente expuesto que el reducto del campo de Sancti Petri sería levantado por el ejército inglés con posterioridad a esta valoración, coordinada con los ingenieros militares españoles. Ellos mismos se encargaron de dotarlo de efectivos, una vez construido, para defender este punto de la Playa de Camposoto.

Esta documentación expone lo siguiente en relación al planteamiento logístico de defensa de la zona de Sancti Petri:

Está al alcance de qualquiera el error que se ha cometido en este punto, construyendo baterías con fosos, expuestas a ser enfiladas y sorprendidas. Aquí deberían hacerse uno o dos reductos buenos, capaces de montar 10 o 15 cañones y de contener a 400 o 500 hombres cada uno, perfectamente seguros contra un golpe de mano y retirados como unas 1.000 yardas de la punta - pueden construirse sin necesidad de madera o albañilería - 500 hombres pueden hacer en seis semanas o dos meses una de estas obras, $y$ es de presumir que la guarnición de este punto, pueda ser siempre semejante número de obrero. (Archivo Histórico Nacional. Signatura. Diversos Colecciones, 120, N.2 Traducción al castellano de la propuesta hecha el 10 de mayo de 1811 por el teniente general Graham....).

Los primeros 3000 soldados, bajo el mando del general Stewart, llegaron el 11 de febrero de 1810, y fueron destinados a la batería del Portazgo, situada en el Puente Suazo. También allí fueron destinados los soldados del Regimiento Portugués de Campomayor. 
La edificación del Reducto inglés constaba, según la leyenda del plano de Vargas Machuca, con una fuerza artillera de 16 cañones de grueso calibre. Del mismo se dice textualmente que:

\section{Los ingleses con el objeto de asegurar la defensa del Campo de Sancti Petri, punto tan importante apoyaron la de la gola de sus obras con este reducto al mismo tiem- po que las precavían de cualquier intento del enemigo por la costa del Sur, se halla artillada con 16 piezas de grueso calibre. (Sancho, 2004: 148).}

Hay que aclarar que el término "gola" es una línea recta imaginaria cuando no tiene parapeto, que une los extremos de los dos flancos en una obra defensiva. El reducto estaba rodeado de un foso y estacada con puente corredizo, claramente representado en el dibujo de Vargas-Machuca. Se aprecia en el plano la distribución de las 16 piezas de artillería en dos flancos diferentes, orientados al oeste y al sur, es decir, para la defensa de una posible incursión por mar. En el interior se representan dos conjuntos de edificaciones. Por una parte, una estancia de mayor tamaño, situada en el sector noreste, y otras tres dependencias, de menor tamaño, en el flanco noroeste. A través del plano de Vargas-Machuca ha sido posible estimar las medidas del recinto interior y exterior del reducto. Los datos aparecen representados en el plano en pies castellanos, medida en uso hasta inicios del siglo XIX equivalente a $0,278 \mathrm{~cm}$, obteniéndose una ocupación del espacio exterior de unos 185 x 130 metros, y otro interior de unos $105 \times 70$ metros.

Como se ha descrito anteriormente, para la construcción de los reductos, según los textos de la época, se utilizaba arena, fango y materiales vegetales, como pitas, fajinas, etc. Estas últimas eran preferidas por los ingenieros militares especialmente para su uso como revestimiento. Otra opción constructiva era usar el material vegetal trenzado en forma de cestones (cilindros llenos de tierra), o los denominados salchichones (fajinas grandes formadas con ramas gruesas). El objetivo de estas técnicas constructivas diversas era servir de refuerzo contra el fuego enemigo. El conjunto se apuntalaba mediante estacas de madera hincadas en el suelo, para darles consistencia y estabilidad.

Sabemos que, para la construcción de este sistema de fortificación, al menos para las baterías de Sancti Petri y Gallineras, fue necesario el aprovi- sionamiento de madera procedente del pinar del Coto de la Barca (Chiclana de la Frontera) (Aragón, 1998: 198). Igualmente se conoce que la batería de Aspiroz (Clavijo, 1960: 369), situada a 150 varas de la de Urrutia, estaba construida con lodo, salchichones y sacos de arena. Además, se utilizaba "vasijería" (restos de cerámica) y tablazón para los parapetos y se fabricaron innumerables cestones, alimentándose los fosos de las baterías con atajos de agua (Pérez, 1978: 286).

Finalmente, y ya en época del Trienio Liberal y del nuevo ataque del ejército francés practicado a San Fernando y Cádiz en 1823, fueron realizadas en el reducto una serie de obras de mejoras (Gil, 2006: 4), pasando entonces a denominarse "Reducto de Lacy", en memoria del héroe de la Guerra de la Independencia Luis de Lacy Gautier, fusilado en Palma de Mallorca en el año 1817, por haberse pronunciado a favor de la Constitución de 1812 (Figura 8).

Se desconoce en qué estado se encontraría el reducto inglés en 1823 cuando se reutilizó, así como en qué consistieron las obras de mejora realizadas, o si se rehabilitaron todas las estructuras documentadas en el plano de Vargas-Machuca o bien se distribuyeron de otra manera los espacios internos de la fortificación, ya que no se la localizado documentación al respecto.

\section{Conclusiones}

La costa atlántica en esta zona del litoral gaditano se caracteriza por playas no confinadas, con flechas o cordones de arena con posibilidades de desplazamientos hacia el interior. El volumen sedimentario y el clima de vientos permiten la creación de campo de dunas. Este aspecto es el que presenta la playa de Camposoto, y los cambios litorales hacen evolucionar el paisaje ante los ojos del simple observador, que puede apreciar, tras un corto número de años, cómo se modifican los escenarios. Es fácil de constatar, por ejemplo, en el crecimiento de la Punta del Boquerón, donde la arena se acumula y tiende a unirse al castillo de Sancti-Petri y a cerrar el acceso, mediante colmatación, de la desembocadura del propio caño. Frenar este proceso natural es imposible, y solo con mantenimientos periódicos de obras de ingeniería marítima como los dragados se consiguió, en un momento determinado y puntual, minimizar su efecto.

Como se ha expuesto en líneas anteriores, la ubicación del reducto obedecía a premisas estra- 


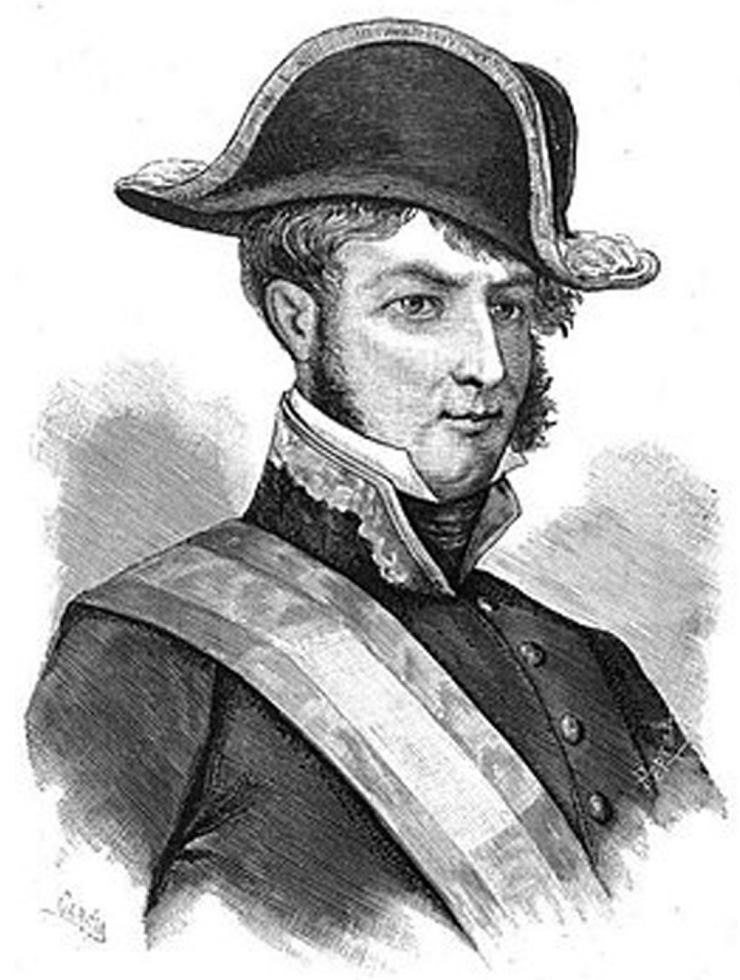

Figura 8. General Luis de Lacy Gautier (1772 -1817). (Fuente: Biblioteca Nacional de España).

tégicas, de defensa y cierre de un posible frente de ataque de las tropas francesas. Las circunstancias generales que vivía el país, unido a la falta de todo tipo de recursos, obligó a levantar un establecimiento defensivo con materiales poco duraderos, pero de fácil obtención, puesto que podían conseguirse en las inmediaciones de la propia construcción. El objetivo principal era poner a resguardo un destacamento que pudiese, con ayuda de algunas piezas de artillería, repeler el paso del enemigo. Cuando se decidió su emplazamiento, éste debía estar situado a una distancia prudencial de la entonces línea de costa, para que no se viese afectado por los embates del mar durante los temporales de invierno.

Siguiendo con el planteamiento teórico expuesto anteriormente para el cálculo de la línea costera a partir de los restos del navío Fougueux, y sumando a los datos y conclusiones de dicho estudio la aparición de los restos del Reducto inglés, se ha analizado el retroceso costero a través tanto de la documentación textual como cartográfica además de contar con el apoyo de las fotografías aéreas, llegando a la conclusión de que esta fortificación se ubicaría a unos 200 metros de la línea de costa a principios del siglo XIX (1823). Por tanto, los datos corroboran un retroceso costero en la zona de localización del reducto de aproximadamente un metro anual (Fernández-Montblanc, 2014: 416).

La acción de la naturaleza condicionó tanto el día a día de las tropas acuarteladas en las defensas, como su final, ya que muchas fueron destruidas por fenómenos naturales o desaparecieron a consecuencia de los cambios producidos en la línea de costa.

Siendo fortificaciones levantadas en lugares muy cercanos al mar, se vieron muy afectadas por temporales, que llevarían aparejados una fuerte acción del oleaje unido a importantes movimientos de arena, dejando apenas unas ruinas visibles o pudiendo incluso hacerlas desaparecer. Así mismo, se verían afectadas por cambios en la línea de costa. Estos son algunos ejemplos de edificaciones costeras afectadas por estos fenómenos en la costa andaluza: la torre del Bobaro o las torres de Punta Entinas (Almería), Llano de Carchuna (Granada), del Río de la Miel (Málaga), las baterías de Chipiona y de Regla (Cádiz) (Gil, 2006: 2), o las de la provincia de Huelva: torre del Río de Oro (Mazagón) y La Higuera (Almonte).

A estos ejemplos de destrucción puede sumarse el Reducto inglés o de Lacy. Su ubicación, tan cercana y expuesta a la línea costera, así como a otros agentes naturales, debieron propiciar su final. 


\section{El reducto inglés de Sancti Petri o de Lacy: una fortificación costera de la Guerra de la Independencia de España en la Playa de Camposoto (San Fernando, Cádiz)}

Solo se conocía su posicionamiento teórico, representado en cartografía de inicios del siglo XIX y únicamente han quedado como testigos de su construcción unas improntas excavadas para levantar parapetos o para profundizar los fosos, así como restos vegetales que formaron parte de los materiales originales de la edificación. Su progresivo desmantelamiento no fue inmediato, puesto que aparece localizado en la cartografía de 1839 anteriormente citada.

A pesar de no haber logrado reconstruir mediante la toma de coordenadas el perímetro de la construcción, tanto por la ubicación de los restos documentados, como por la comparación de su posicionamiento con la cartografía consultada, podemos afirmar que la estructura hallada se corresponde con el "Reducto inglés de Sancti Petri", también denominado posteriormente como "de Lacy", que formaba parte de la primera línea de defensa contra el asalto de las tropas de Napoleón a las ciudades de San Fernando y Cádiz.

Además de parte la zona perimetral del reducto, solo fue posible detectar la presencia de la impronta de un espacio habitacional de tamaño reducido en el interior (Figura 9), que podría co- rresponderse con alguna de las edificaciones que aparecen representadas en el plano de Vargas.

Otro claro ejemplo del avance del mar en este extremo de la Punta del Boquerón y de fecha mucho más reciente, son los dos búnkeres cercanos al reducto, afectados también por el retroceso costero de esta zona. Fueron construidos durante la Guerra Civil española para proteger la zona franquista de un posible ataque republicano. También se utilizó durante la posguerra, ante una posible invasión aliada, y actualmente se localizan ambos en zona intermareal.

Desde la perspectiva de la protección, y en relación a los restos arqueológicos documentados, señalar que toda la información relativa a nuevos yacimientos pasan a completar la Carta Arqueológica subacuática, para su incorporación a MOSAICO, el Sistema de Gestión e Información de los Bienes Culturales de Andalucía (anteriormente ARQUEOS y SIPHA). Desde 2009 se integran en esta única herramienta las actuaciones necesarias para la gestión y documentación de los bienes culturales llevadas a cabo desde la Secretaría General de Cultura, por parte de la Dirección General de Bienes Culturales y Museos, el Instituto Andaluz

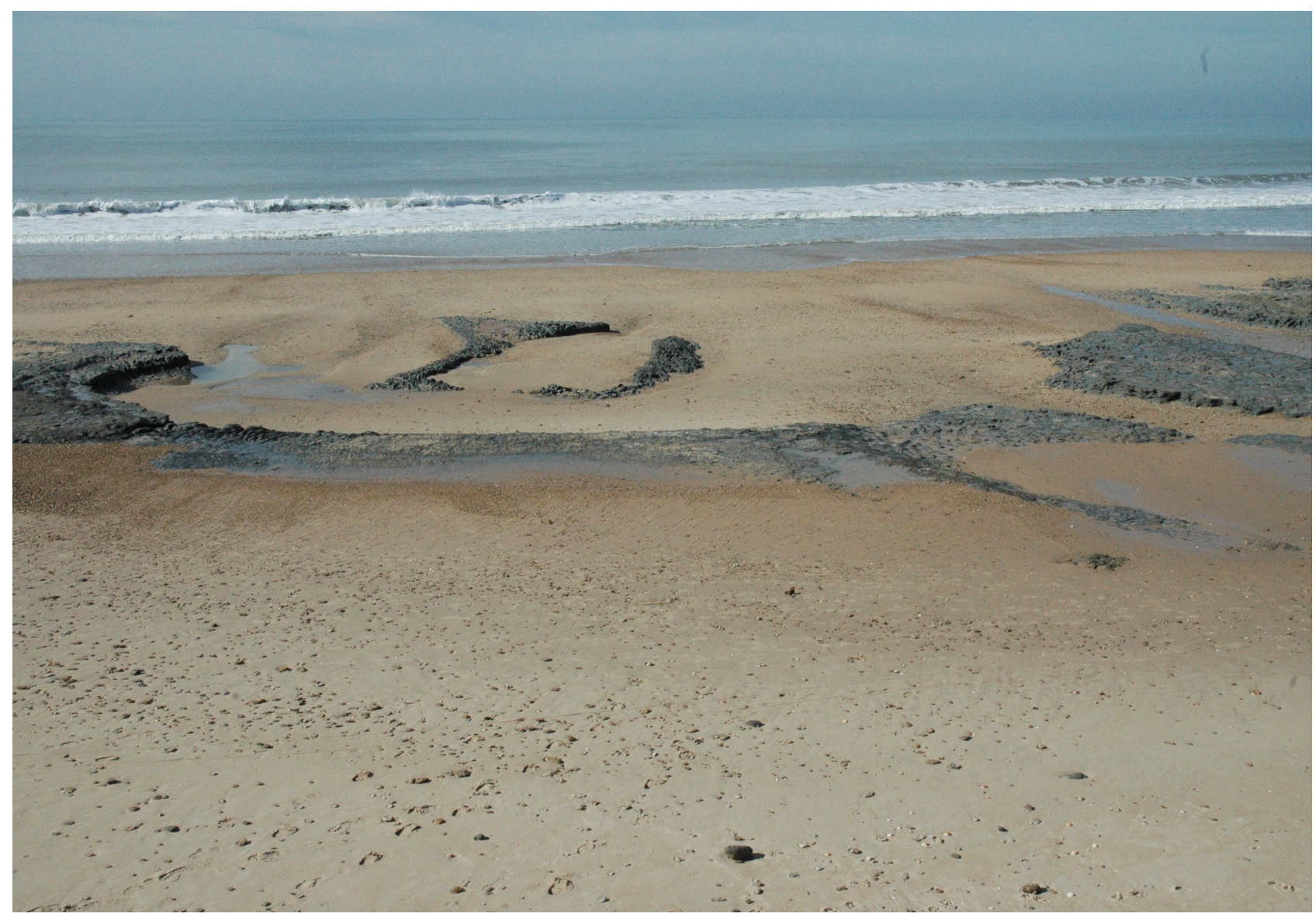

Figura 9. Imagen de la impronta de un espacio interior. (Fuente: A. Sáez). 
del Patrimonio Histórico y las Delegaciones Territoriales de Cultura y Patrimonio Histórico.

\section{Agradecimientos}

Queremos dedicar este artículo a D. Antonio Sáez Espligares, arqueólogo y técnico del Museo Municipal de San Fernando (Cádiz), que ha empleado toda su vida profesional en la investigación y defensa del Patrimonio Histórico de esta población (Figura 10).

Sin sus paseos por la Isla de León, no se hubiese descubierto e identificado este reducto militar, cuya huella en la zona intermareal de la Playa de Camposoto supieron ver sus ojos, interpretar sus conocimientos y documentar su cámara.

\section{Fuentes de información}

\section{Fuentes bibliográficas}

ALONSO VILLALOBOS, Carlos; GRACIA, Francisco Javier y BENAVENTE, Javier. 2009: “Evolución histórica de la línea de costa en el sector meridional de la Bahía de Cádiz". Revista Atlántica-Mediterránea de Prehistoria y Arqueología Social, 11, pp. 13-37.

ARAGÓN GÓMEZ, Jaime. 1998: “Vicisitudes económicas del ejército y la marina durante el sitio de Cádiz y la Isla de León por los franceses". En XIII Encuentro de Historia y Arqueología, pp. 189-208. Ayuntamiento de San Fernando. San Fernando.

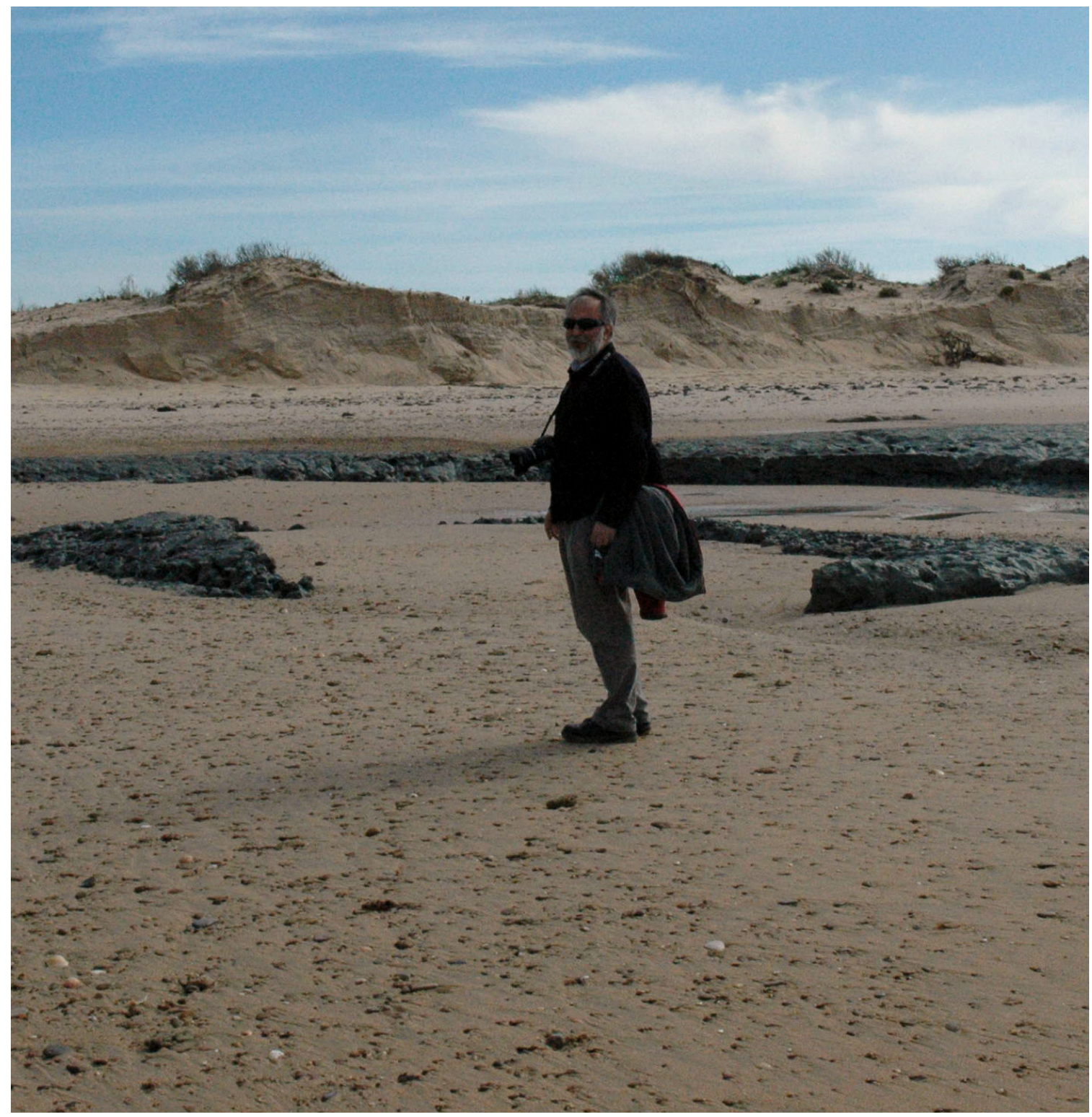

Figura 10. Antonio Sáez en la zona del hallazgo del Reducto inglés. (Fuente: Fondo gráfico IAPH-CAS). 
BETHENCOURT, Manuel; GRACIA, Javier; DEL RÍO, Laura; BENAVENT,. Javier. 2011: "Los restos de naufragios históricos como indicadores del paleolíneas de costa. El caso del Fougueux (Bahía de Cádiz)". En I. MONTOYA, I. RODRÍGUEZ y M. J. SÁNCHEZ (eds.): Avances en Geomorfología Litoral Actas VI Jornadas de Geoarqueología litoral, pp. 47-50. Barcelona.

CLAVIJO CLAVIJO, Salvador. 1960: Historia de San Fernando. Ayuntamiento de San Fernando. San Fernando.

DURÁN LÓPEZ, Fernando (coord.). 2012: La Batalla de Chiclana (5 de marzo de 1811): estudios $y$ testimonios reunidos con motivo del bicentenario. Servicio de Publicaciones de la Universidad de Cádiz. Cádiz.

FERNÁNDEZ-MONTBLANC, Tomás; BETHENCOURT, Manuel; DEL RÍO; Laura, BENAVENTE, Javier; GRACIA, Javier. 2014: "Study of the Fougueux wreck (1805) and the remains of the Fort Lacy (1813) as indicators of paleocoastline". En Actas del V Congreso Internacional de Arqueología Subacuática, pp. 406-418. Ministerio de Educación Cultura y Deporte, Subdirección General de Documentación y Publicaciones. Cartagena.

GALLARDO ABÁRZUZA, Mercedes; MÁRQUEZ CARMONA, Lourdes. 2005: "Los naufragios de la Batalla de Trafalgar". PH : Boletín del Instituto Andaluz del Patrimonio Histórico, 55, pp. 86-92.

GIL ALBARRACÍN, Antonio. 2006: "Destrucción y reconstrucción del dispositivo defensivo en el litoral andaluz durante la primera mitad del siglo XIX". VI Jornadas (on-line) sobre fortificaciones organizadas por Aforca. Progreso y evolución de las armas, fortificaciones y buques de guerra, durante el siglo XIX (desde la Guerra de la Independencia hasta el reinado de Alfonso XII). http://www.jornadasaforca.org/ pon06 12.doc.

IZAGUIRRE LACOSTE, Manuel; RIETH, Eric; RODRÍGUEZ MARISCAL, Nuria. 2010: "Investigaciones en el pecio de Camposoto: hacía la identificación del navío francés Fougueux". PH: Boletín del Instituto Andaluz del Patrimonio Histórico, 75, pp. 94-107.

IZCO REINA, Manuel Jesús; ESPINOSA DE LOS MONTEROS SÁNCHEZ, Francisco. 2012: $M a-$ tagorda 1810: un episodio de la Guerra de Independencia en Andalucía. Ayuntamiento de Puerto Real. Puerto Real.
LÓPEZ MORENO, Miguel Ángel. 2013. Blog del Milano. "Baterías de la Real Isla de León: Dispuestas por la autoridad durante el asedio francés de 1810-1812". https://milan2.es/Baterias Isla/Baterias.html.

MÁRQUEZ CARMONA, Lourdes. 2008: "Recuerdos de un timonel: Michel Maffiotte y la rendición de la escuadra de Rosily en la Batalla de la Poza de Santa Isabel (1808)". Trocadero: Revista de historia moderna y contemporánea, 20, pp.33-44.

MÁRQUEZ CARMONA, Lourdes. 2015: “Un comandante del batallón del cuerpo de ingenieros napoleónico en Matagorda (Puerto Real): Garbé y el Sitio de Cádiz". Revista Matagorda, 1, pp. 79-106.

MÁRQUEZ CARMONA, Lourdes. 2020: Recordando un olvido: pontones prisiones en la Bahía de Cádiz. 1808-1810. Círculo Rojo. Almería.

MÁRQUEZ CARMONA, Lourdes; ALONSO VILLALOBOS Carlos; BENÍTEZ, David. 2016: "El patrimonio cultural marítimo de la Bahía de Cádiz según la visión de un hidrógrafo de $\mathrm{Na}$ poleón: El vicealmirante Rosily". Revista de historia de El Puerto, 56, pp. 31-60.

PÉREZ DE SEVILLA Y AYALA, Vicente. 1978: La Artillería española en el sitio de Cádiz. Diputación Provincial. Instituto de Estudios Gaditanos. Cádiz.

RAMÍREZ, Pedro J. 2014: La desventura de la libertad: José María Calatrava y la caída del régimen constitucional español en 1823. La esfera de los libros. Madrid.

ORTEGA FELÍU, Pilar; ALADRO PRIETO, José Manuel. 2012: Guía de las Fortificaciones y Sistemas de Defensa de la Bahía de Cádiz. Consorcio para la conmemoración del Bicentenario de la Constitución de 1812 y Colegio Oficial de Arquitectos de Cádiz. Cádiz.

RUIZ AGUILAR, Susana; HIGUERAS-MILENA, José Manuel; MÁRQUEZ CARMONA, Lourdes. 2005: "Control y seguimiento de las obras de dragado del Caño de Sancti Petri, Chiclana de la Frontera (Cádiz). Prospecciones subacuáticas previas y posteriores al dragado". Anuario Arqueológico de Andalucía. Tomo III. Volumen I. Actividades de Urgencia, pp. 86-92.

SANCHO RODA, José. 2004: El Atlas de las Fortificaciones de La Isla de San Fernando: de Carlos Vargas Machuca. Ayuntamiento. Gerencia Municipal de Urbanismo. San Fernando. 


\section{Fuentes manuscritas}

"Traducción al castellano de la propuesta hecha el 10 de mayo de 1811 por el teniente general Graham, del Cuerpo de Ingenieros del Ejército británico, para mejorar las fortificaciones de la línea defensiva en torno a Cádiz, particularmente las que cubren el recinto del arsenal de La Carraca, Puente Suazo, Portazgo y Sancti -Petri. 1811-06, Isla de León Archivo Histórico Nacional Signatura: Diversos Colecciones, 120, N.2". En: Web PARES. Colección digital "La Guerra de la Independencia a través de los fondos del Archivo Histórico Nacional". http:// pares.mcu.es/GuerraIndependencia/catalog/ exp/show/4989072.

\section{Fuentes hemerográficas}

GLICERIO CONDE MORA, Francisco. "Un puente en la Punta del Boquerón”. Diario de Cádiz, 14 de marzo de 2015. https://www.diariodecadiz. es/opinion/articulos/puente-Punta-Boqueron_0 898110614.html.

LACY, Lluis, teniente general. "La Ilustración Catalana". Any 2. N. 38. 20/07/1881. P. Biblioteca Nacional de España. Hemeroteca Digital. http://hemerotecadigital.bne.es/issue.vm?i$\underline{\mathrm{d}=0001356541 \& \text { search=\&lang=es. }}$.

\section{Informes y memorias}

GONZÁLEZ GALLERO, Raúl. 2009. Memoria preliminar del Proyecto de prospección arqueológica subacuática en aguas de la playa de Camposoto. San Fernando. Cádiz. Delegación de Cultura de la Junta de Andalucía. Cádiz.

MARTÍ SOLANO, Josefa: MÁRQUEZ CARMONA, Lourdes. 2010. Informe sobre la fortificación costera denominada Reducto Inglés o de Lacy. Playa de Camposoto (San Fernando. Cádiz). Centro de Arqueología Subacuática. Instituto Andaluz del Patrimonio Histórico. Cádiz.

\section{Fuentes cartográficas}

"Planimetría del Reducto inglés incluida en la obra realizada por Carlos Vargas Machuca. Reducto inglés de Sancti Petri. Lámina 45". Biblioteca Virtual del Patrimonio Bibliográfico. Ministerio de Cultura. España. https://bvpb.mcu.es/ en/consulta/registro. cmd?id=448131.
"Plan de Cadiz et de ses environs : comprenant les Travaux exécutés pendant le Siége de cette Place ainsi que les Positions occupeés par les Armées Françaises de Terre et de Mer: réduit d' aprés celui levé a l'Echelle du 1/10.000 par les Offrs. du Corps Royal des Ingenieurs. Geoges français dans la Campagne de 1823 Cádiz (Bahía). Imprimerie Litographie de G. Engelmann ed, [1823?]". Gallica, Biblioteca Nacional Francia. https://gallica.bnf.fr/ark:/12148/ btv1b8492414k/f1.item.zoom.

"Plan de l'attaque de l'ille de Leen dirigés per l'embocuchure du Sn. Petri. 1823. La Artillería española en el sitio de Cádiz/Vicente Pérez de Sevilla y Ayala". Diputación Provincial. Instituto de Estudios Gaditanos. Cádiz.

"Mapa de los alrededores de Cadiz/Dufour, Auguste-Henri (1798-1865). [s.l.][s.n.], 1839". Bibliothèque nationale de France, département Cartes et plans, GEC-2534. ark:/12148/ btv1b530296275. https://gallica.bnf.fr/ ark: $/ 12148 /$ btv1b530296275.r $=$ plan $\% 20$ cadix\%20dufour?rk=21459;2.

"Plan of the bay and harbour of Cadiz: exhiviting the state of the forts and works, when the English and Spaniards endeavoured to make Marshal". By mr. William Henry Smith; Davies sculp; published by Benj. Davies and by R. Rowe. 181. Editor digital Institut Cartogràfic de Catalunya (ICC). https://cartotecadigital.icgc.cat/digital/collection/espanya/id/1022/.

\section{Fuentes gráficas}

"Prise du fort Sancti Petri. Combat naval 21 septembre 1823". Gravure Versailles. 